\title{
Dimensions of Psychological Capital in the Nurses Employed in Psychiatric Hospitals and the Correlations with Demographical Variables
}

\author{
Ranaa Jafarizadeh ${ }^{1},{ }^{*}$ Narges Sadeghi ${ }^{2}$, Mehrdad Azarbarzin $^{3}$
}

\begin{abstract}
Background \& Aims: Psychological capital defined as the positive, flexible, and realistic approach toward life, which plays a key role in the outcomes of individual functions. Given the importance of improving the dimensions of psychological capital in nurses and its key role in the quality of nursing care, the present study aimed to assess the dimensions of psychological capital in nurses.

Materials \& Methods: This descriptive, cross-sectional study was conducted on 95 qualified nurses who were selected via convenience sampling in 2018. Data were collected using a demographic questionnaire and McGee psychological capital scale. Data analysis was performed in SPSS version 22 using Pearson's correlationcoefficient and independent $t$-test at the significance level of $5 \%$.

Results: The mean total score of psychological capital in the subjects was $116.89 \pm 17.86$, which indicated the high level of psychological capital. Moreover, the findings showed that the level of psychological capital was moderate in 44 nurses (46.8\%), while it was high in 50 nurses (53.2\%). However, no significant correlations were observed between psychological capital, age, and job experience. In addition, the mean score of psychological capital had no significant difference between the male and female subjects $(\mathrm{P}>0.05)$.

Conclusion: The findings of this research could help senior officials to identify and better recognize each component of psychological capital, so that they could use these elements as a strategy to improve the quality of patient care in psychiatric health sectors.
\end{abstract}

Keywords: Nurse, Psychological Capital, Hospital, Psychiatric Ward

\section{Conflict of Interest: No}

How to Cite: Jafarizadeh R, Sadeghi N, Azarbarzin M. Dimensions of Psychological Capital in the Nurses Employed in Psychiatric Hospitals and the Correlations with Demographical Variables. Iran Journal of Nursing. 2019; 31(116):40-48.

Received: 15 Nov 2018

Accepted: 13 Feb 2019

\footnotetext{
1. MS Student in Psychiatric Nursing, Community Health Research Center, Islamic Azad University Isfahan (Khorasgan) Branch, Isfahan, Iran

2. Assistant Professor, Community Health Research Center, Islamic Azad University, Isfahan (Khorasgan) Branch, Isfahan, Iran. (*Corresponding author) Tel: 09131091715 Email: n45sadeghi@yahoo.com

${ }^{3}$. Assistant Professor, Nursing and Midwifery Sciences Development Research Center, Najafabad Branch,Islamic Azad University, Najafabad, Iran
} 


\section{ابعاد سر مايه روانشناختى در برستاران شاغل در بيمار ستان روانِزشكى و ارتباط آن با متغير هاى جمعيت شناختى \\ رعنا جعفرى زاده'، **ركس صادقى '، مهرداد آذربرزينَ"}

جكيده

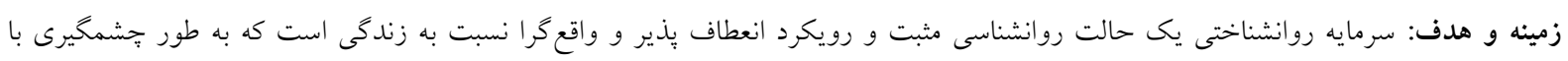

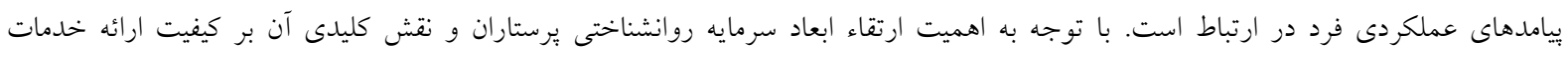

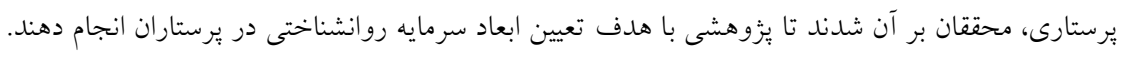

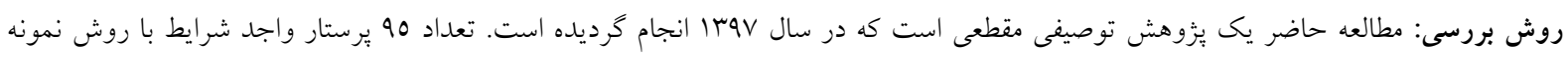

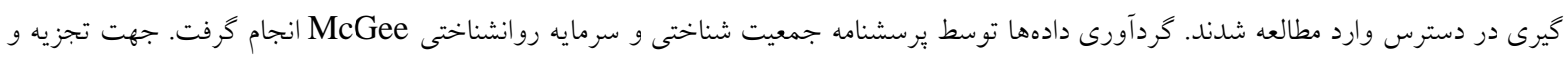

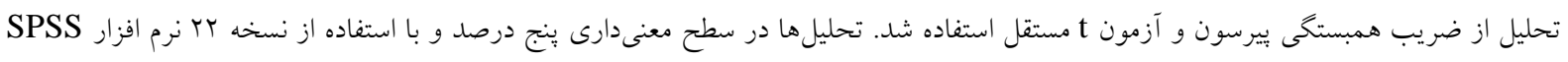
انجام شد.

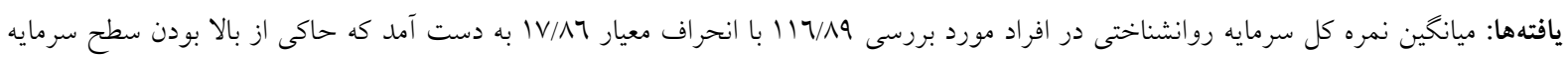

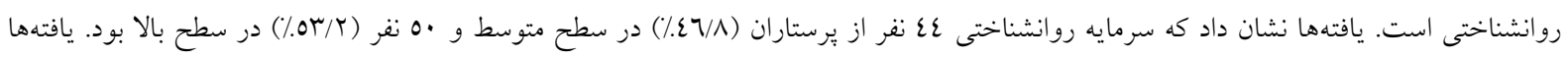

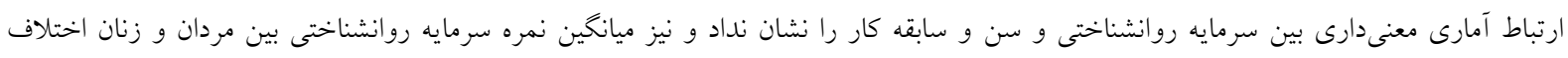

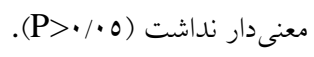

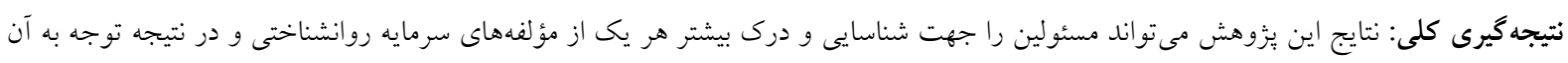

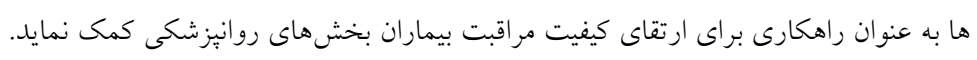

كليد وازٔهها: يرستار، سرمايه روانشناختى، بيمارستان، بخش روانيزشكى.

تعارض منافع: ندارد

تاريخ دريافت: عV/N/T

تاريخ يذيرش:

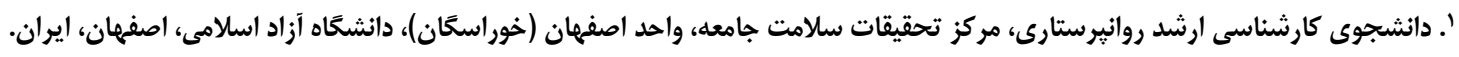

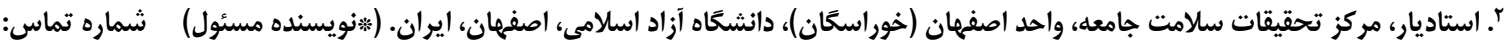


اختلالات بارانوئيدِ بيشترى را تجربه مىكنند. در نتيجه،

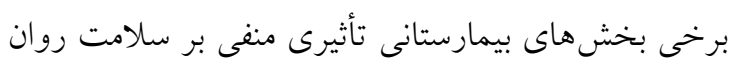

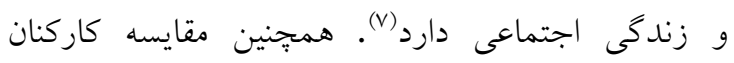

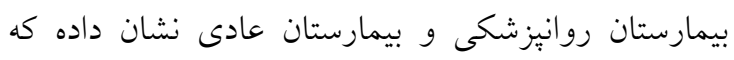

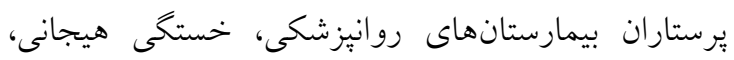

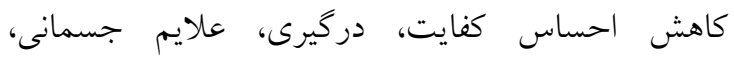
اضطراب و افسردگى بيشترى را نسبت به بيمارستانهاى

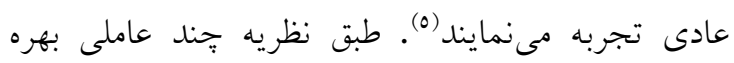

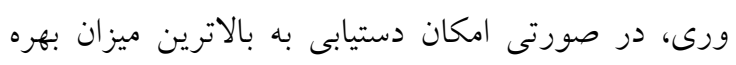

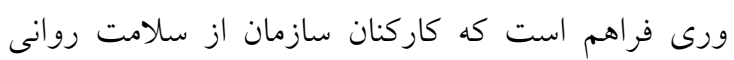

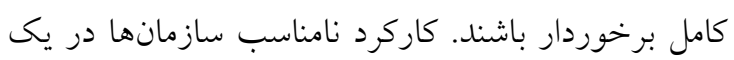

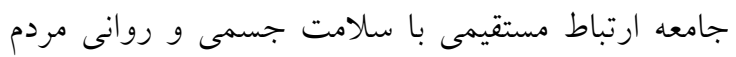

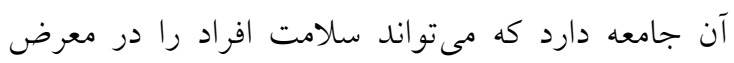

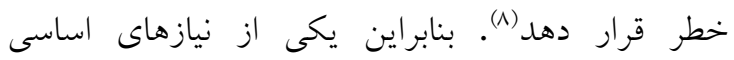

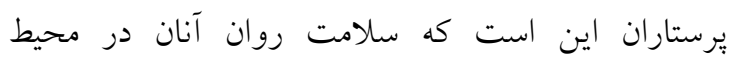
كارشان، در محدودهه مطلوبى حفظ شود (ع).

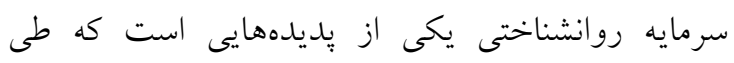

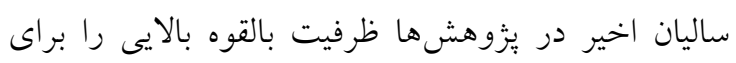

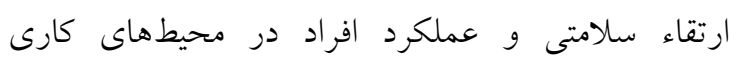

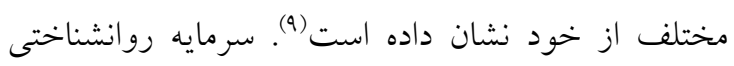

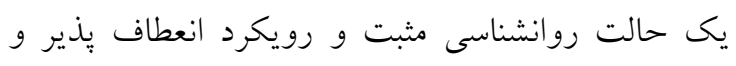

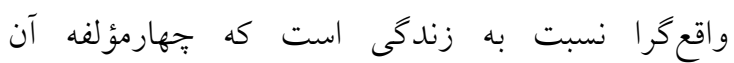

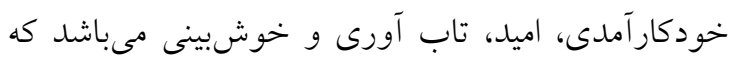

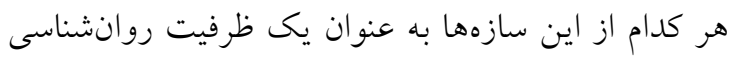
مثبت در نظر گرفته مىشوند و داراى مقياس اندازه گيرى معتبر هستند. اين مؤلفهها مبتنى بر نظريه و تحقيق بوده و

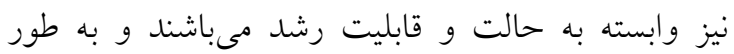

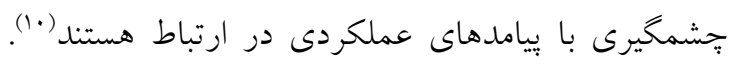

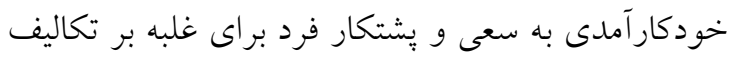

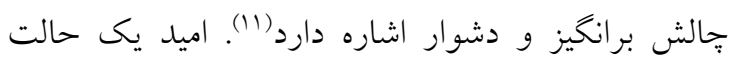
انخيزشى مثبت است كه در دستيابى به اهداف مورد نظر از طريق روشهاى مختلف كمى مى كند (rا). تاب آورى مدرد

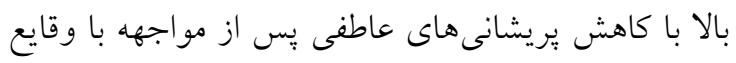

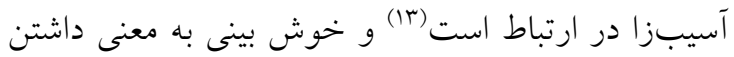

\section{مقدمه}

مشاغلى كه در آن روابط اجتماعى كسترده و ارتباط بين

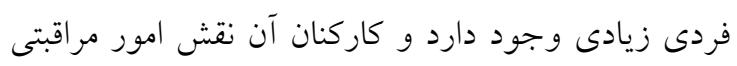

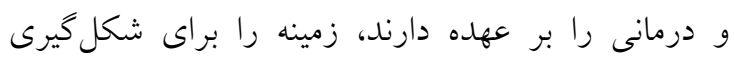

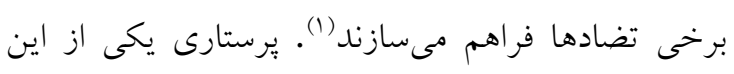

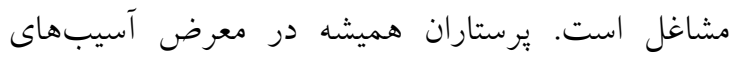

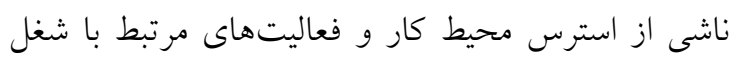

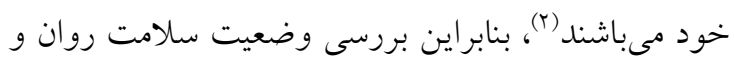

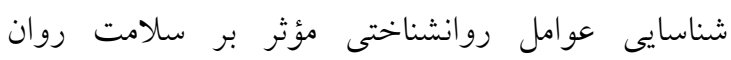

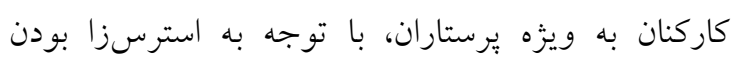

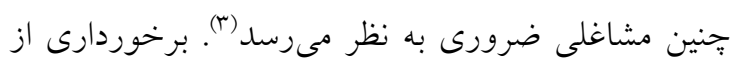

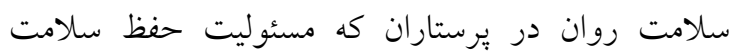
مددجويان را به عهلده دارند، بسيار حايز اهميت است زيرا اين گروه از كاركنان عرصه سلامت بايد ارتباطات بين فردى مؤثر داشته باشند و ارتباط سازنده آنان با ساير

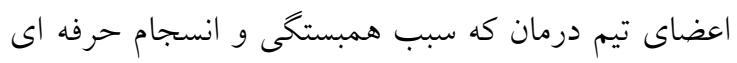

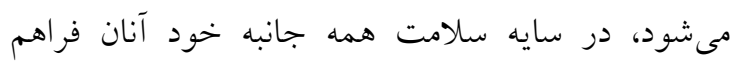

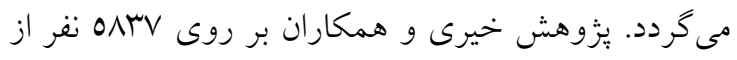

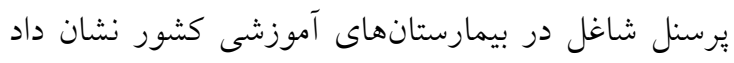

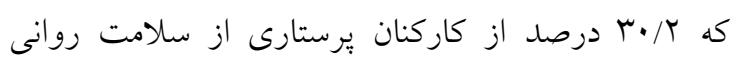

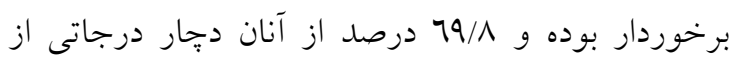

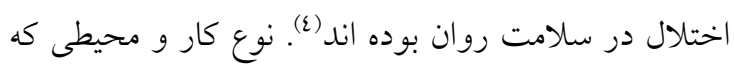

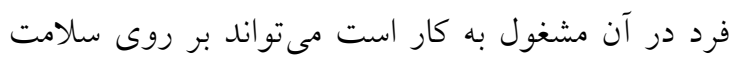

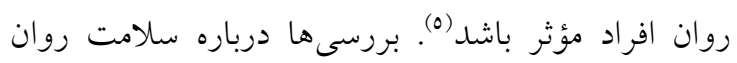
يرستاران نشان مىدهد كه در شرايط كارى يكسان، افراد

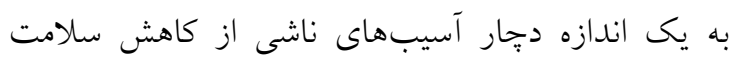

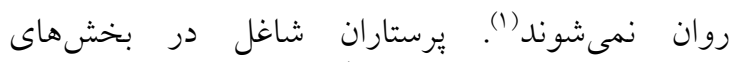

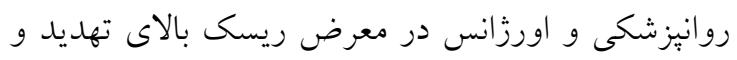

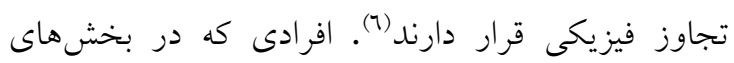

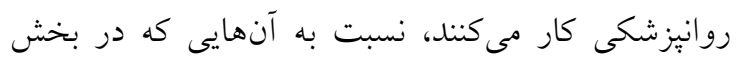

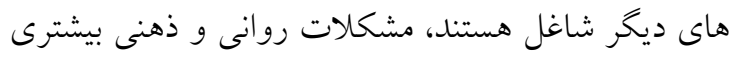

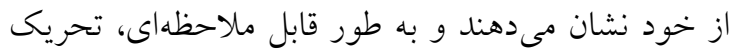
يذيرى، اختلال جسمانى سازى، اختلال وسواس فكرى، حساسيت بين فردى، اضطراب، تغييرات خلق و خو و و 


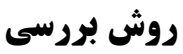

مطالعه حاضر يك ئزوهش مقطعى است كه در سال IraV آزاد اسلامى واحد اصفهان (خوراسگان) با شناسه

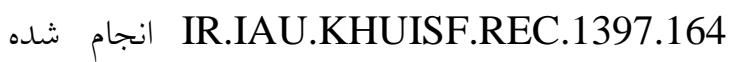

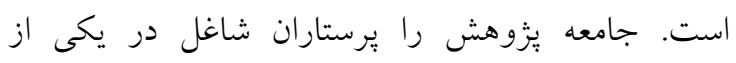

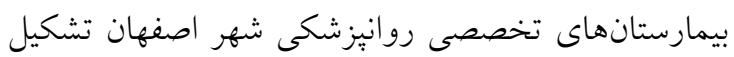

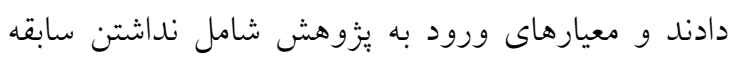
مصرف داروهاى روانيزشكى، شاغل بودن در بخش روانيزشكى، داشتن حداقل يك سال سابقه كار در بيمارستان به عنوان يرستار و رضايت به شركت در

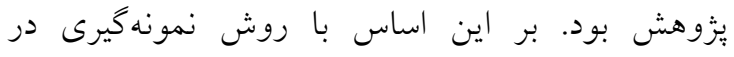
دسترس، تعداد عq يرستار واجد شرايط وارد مطالعه شده

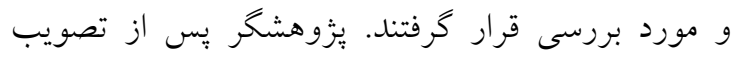

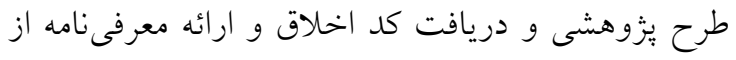

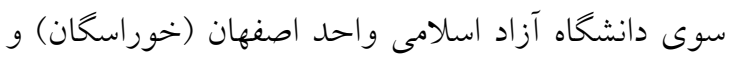

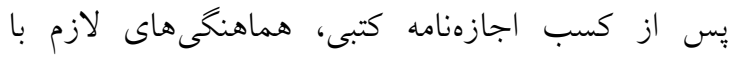

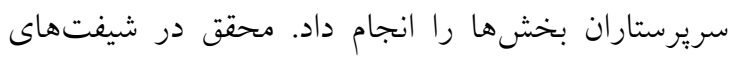
صبح و عصر و شب با كسب اجازه از سريرستار، اقدام

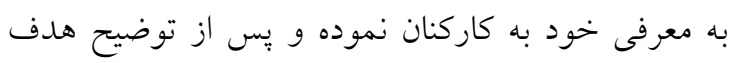

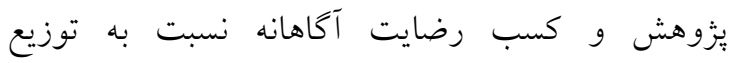
يرسشنامها اقدام كرد و وِرسشنامهها را در در اختيار آنان

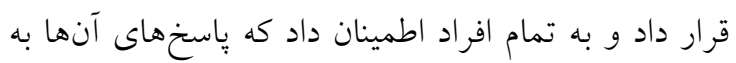
طور محرمانه نزد يزووهشخر باقى خواهد ماند واند.

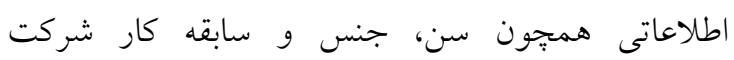

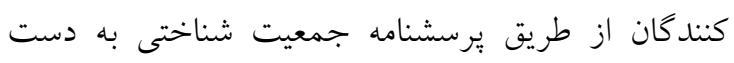

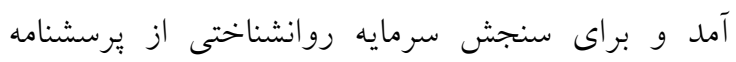

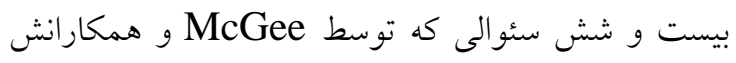

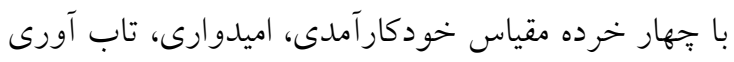
و خوش بينى ساخته شده است، استفاده شد. در اين

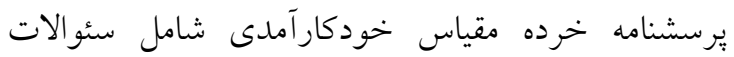
شماره ا تا V، خرده مقياس اميدوارى شامل سئوالات شماره ^ تا عا، خرده مقياس تاب آورى شامل سئوالات شماره 10 تا.ب و خرده مقياس خوش بينى شامل
انتظارات مثبت براى نتايج و بيامدها است و اين بيامدها

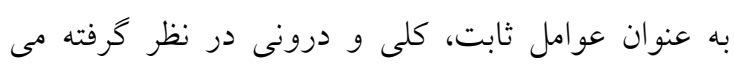

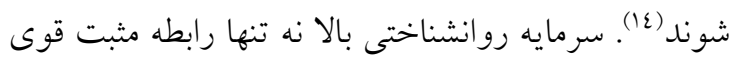

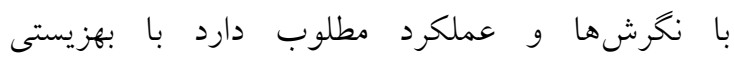
روانشناختى كاركنان نيز ارتباط دارد و و روابط منفى مانى كاركنان با بدبينى، استرس و اضطراب افراد و و يكى سرمايه

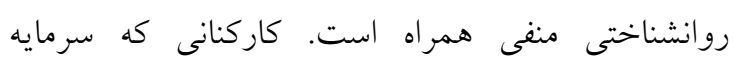

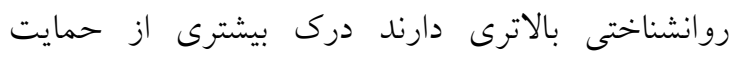

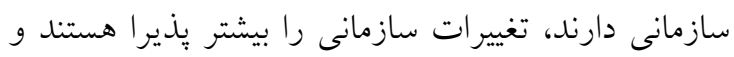
در دستيابى به موفقيت كمك مى كنند. همجنين سرمايه روانشناختى بالا ممكن است يكى منبع روانشناختى باشد دمديك كه تأثير مثبتى بر اشتياق شغلى كاركنان دارد (10). مطالعات متعددى در زمينهى مديريت نشان مى دهند كه بتهي

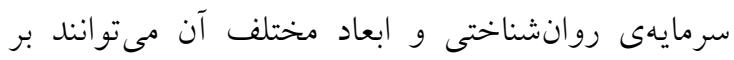
روى عملكرد كارى و رفتارهاى رهبران و كاركنان تأثير

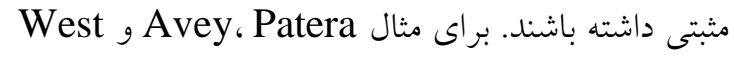

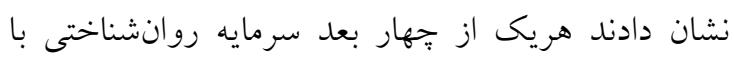

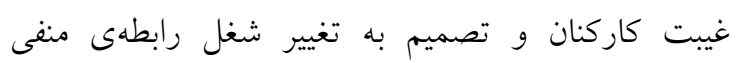
دارد(ז'). در سالهاى اخير مطالعات بسيارى انجام شده

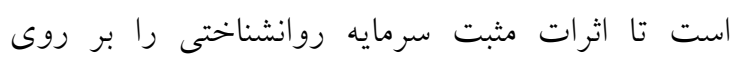
رفتارهاى كارى و نتايج سلامت شغلى در برستاران در

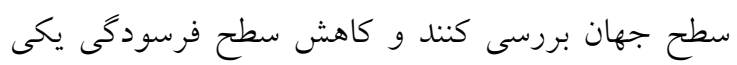

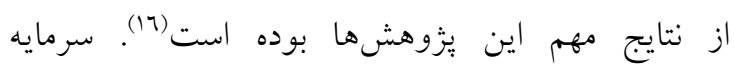

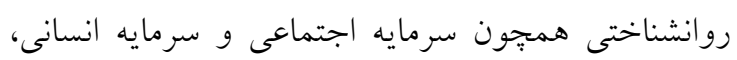

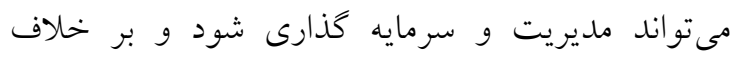

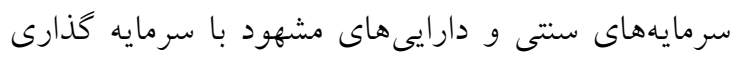

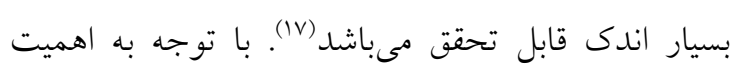

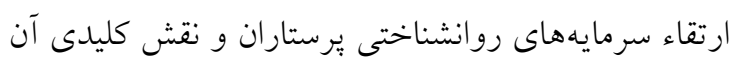

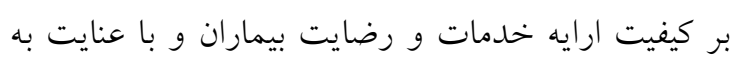
اين نكته كه كار در بخشهاى روانيزشكى مىتواند

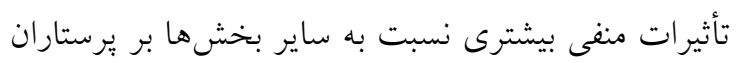

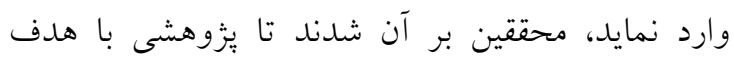

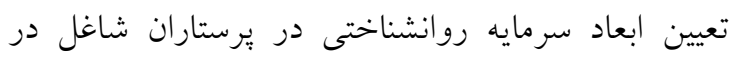
بيمارستان روانيزشكى انجام دهند. 
نمرات T7 تا 79 نشان دهنده سرمايه روانشناختى بايين،

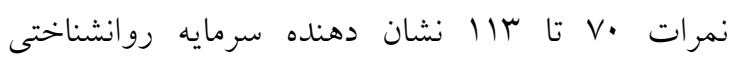

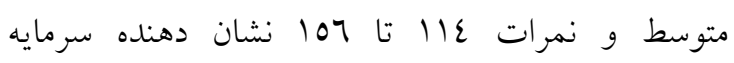

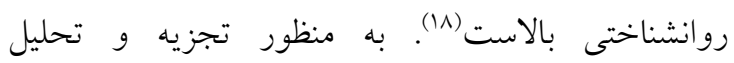

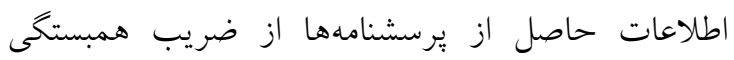

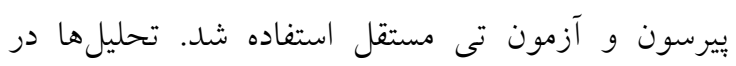

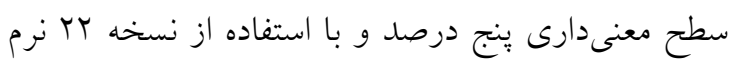

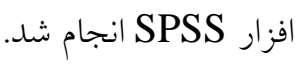

\section{يافتهها}

دامنه سنى افراد مورد بررسى از عَ تا به سال با ميانخين عro/ع و انحر اف معيار V/00 سال بود. ميانخين سابقه كار

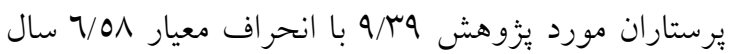

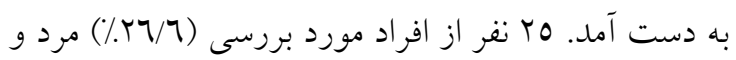

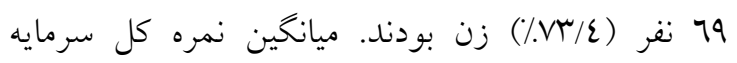

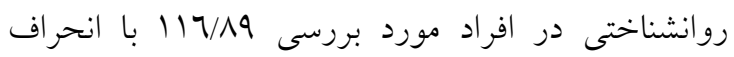

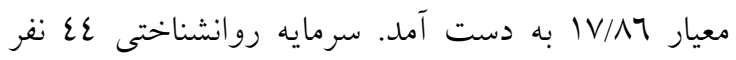

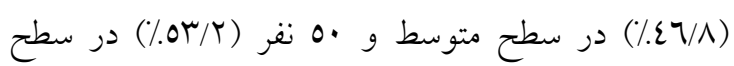

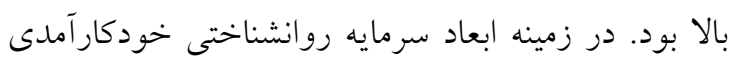

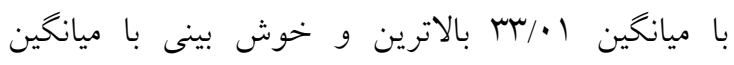
(حادول ro/7.

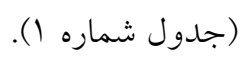

سئوالات شماره آ تا TYY مى باشند. براى به دست آوردن

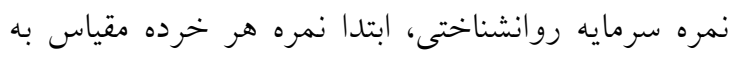

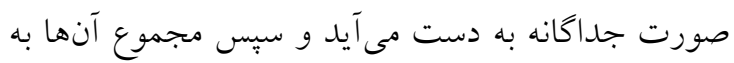

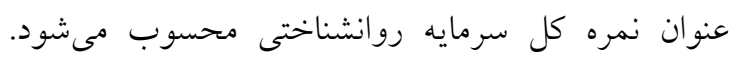
McGee جرخش واريماكس بر روى بيست و شش سئوال اين

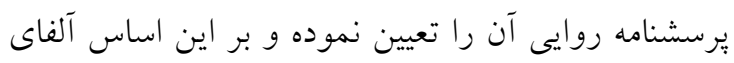

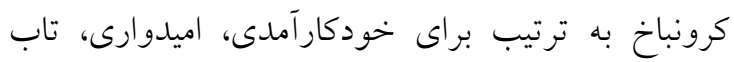

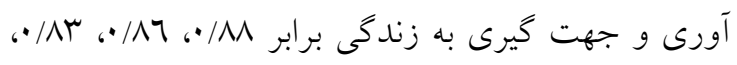

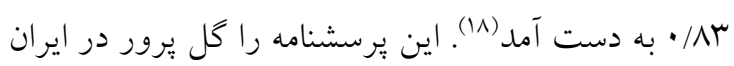

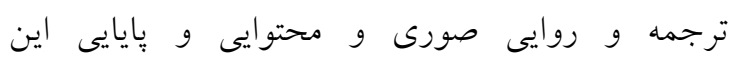
يرسشنامه را بررسى و تأييد نموده است. بر اساس ورئ واين

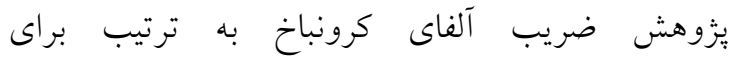

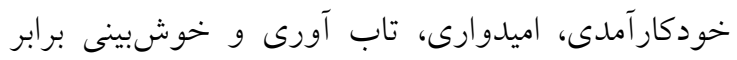

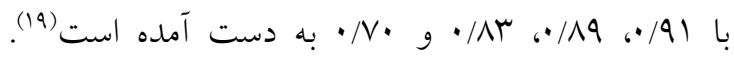

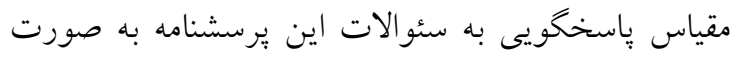

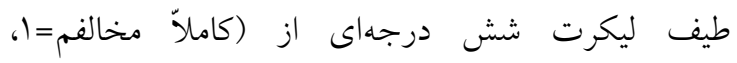

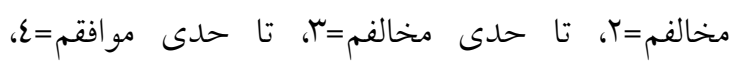

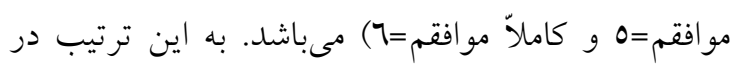

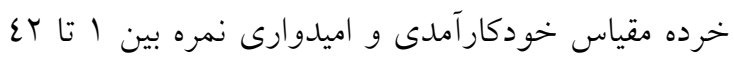

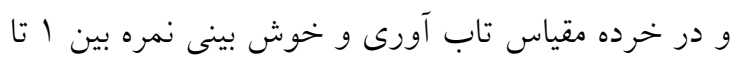

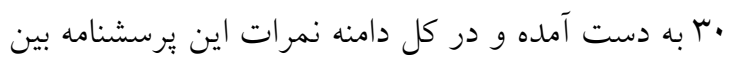

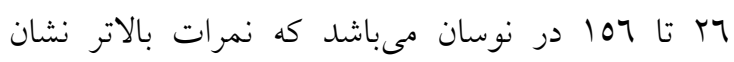

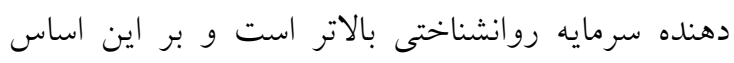

جدول شماره ا: ميانكين نمره كل سرمايه روانشناختى و ابعاد آن در يرستاران

\begin{tabular}{|c|c|c|c|c|}
\hline انحر اف معيار & ميانغين & 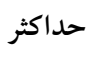 & حداقل - & سرمايه روانشناختى و ابعاد آن \\
\hline IV/AT & $117 / \wedge 9$ & 107 & $v^{r}$ & نمره كل سرمايه روانشناختى \\
\hline$\varepsilon / \neg r$ & $m / \cdot 1$ & $\varepsilon r$ & r & خود كارآمدى \\
\hline $0 / T \wedge$ & 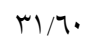 & $\varepsilon r$ & 17 & 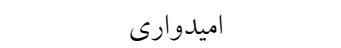 \\
\hline $0 / T_{0}$ & $r \tau / \neg \Lambda$ & r & 7 & تاب آورى \\
\hline $0 / .0$ & ro/7. & r & $1 \varepsilon$ & خوش بينى \\
\hline
\end{tabular}

(جدول شماره Y). هم:حنين آزمون تى مستقل نشان داد كه ميانخين نمره كل سرمايه روانشناختى و ابعاد آن بين مرد و زن اختلاف معنى مارى وجود نداشت (0> • (P)
ضريب همبستخى بييرسون نشان داد كه بين نمره كل سرمايه روانشناختى و ابعاد آن با سن و سابقه كار افراد مورد بررسى رابطه معنىدارى وجود نداشت (0> • (P) 
جدول شماره ؟: ضريب همبستكى بيرسون بين نمره سرمايه روانشناختى برستاران با متغيرهاى سن و سابقه كار آن ها

\begin{tabular}{|c|c|c|c|c|}
\hline \multicolumn{2}{|c|}{ سابقه كار } & \multicolumn{2}{|c|}{ 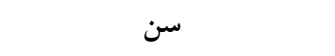 } & \multirow[t]{2}{*}{ ابعاد سرمايه روانشناختى } \\
\hline $\mathbf{P}$ & $\mathbf{R}$ & $\mathbf{P}$ & $\mathbf{R}$ & \\
\hline$\cdot / M$ &.$/ .17$ & $\cdot / \mathrm{N} 7$ &.$- / . \mu r$ & نمره كل سرمايه روانشناختى \\
\hline$\cdot / \mathrm{TV}$ & $\cdot / \cdot \varepsilon \varepsilon$ & $\cdot / 7 \varepsilon$ & $\cdot / \cdot \varepsilon 9$ & خود كار آمدى \\
\hline$\cdot / \mathrm{VV}$ & 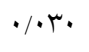 & $\cdot / 91$ & $-\cdot / \cdot r$ & اميدوارى \\
\hline$\cdot 101$ &.$/ .0 \mathrm{~V}$ & $\cdot / \wedge$ &.$- / .+7$ & تاب آورى \\
\hline$\cdot / \varepsilon \wedge$ & $\cdot / \cdot v \varepsilon$ & $\cdot \pi r$ & $-\cdot / 1 Y \Lambda$ & 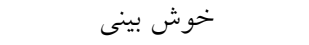 \\
\hline
\end{tabular}

جدول شماره ऍا: ميانكين نمره سرمايه روانشناختى در رستاران مورد مطالعه و مقايسه آن بر حسب جنس آنا

\begin{tabular}{|c|c|c|c|c|c|c|}
\hline \multicolumn{2}{|c|}{ آزمون t مستقل } & \multicolumn{2}{|c|}{ خانم } & \multicolumn{2}{|c|}{ آقا } & \multirow[b]{2}{*}{ 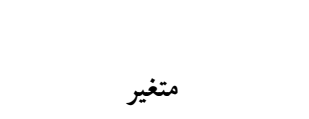 } \\
\hline $\mathbf{P}$ & $\mathbf{T}$ & انحر اف معيار & ميانغين & انحراف معيار & ميانخين & \\
\hline.$/ \cdot 9$ & $1 / V \varepsilon$ & $1 \mathrm{~V} / 0 \varepsilon$ & $11 \varepsilon / 91$ & $1 N / \cdot 0$ & $\mid Y T / I V$ & نمره كل سرمايه روانشناختى \\
\hline$\cdot / v$ & $\cdot / / q$ & $\varepsilon / \varepsilon \varepsilon$ & $M r / q$. & $0 / 11$ & TM/MT & خودكارآ مدى \\
\hline.$/ .0 r$ & $1 / 9 V$ & $\Delta \mu r$. & $r \cdot / 9 V$ & $\varepsilon / 91$ & רז/א & اميدوارى \\
\hline.$/ \cdot 7$ & $1 / 9 \varepsilon$ & $0 / 4 q$ & $r v / \cdot 0$ & $\varepsilon / 0 r$ & $r \Lambda / \varepsilon$. & تاب آورى \\
\hline .1 .9 & $1 / V \varepsilon$ & $0 / 14$ & $r 0 / \cdot 7$ & $\varepsilon / 09$ & $\mathrm{rV} / \cdot 9$ & خوش بينى \\
\hline
\end{tabular}

و همكاران كه با هدف "تعيين نقش ميانجى سرمايه

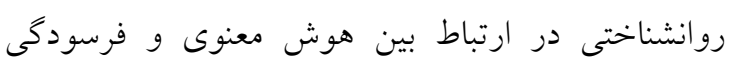

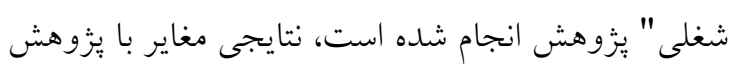

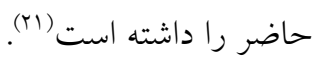

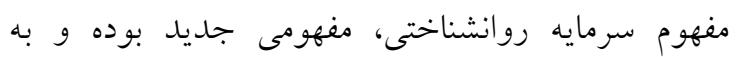

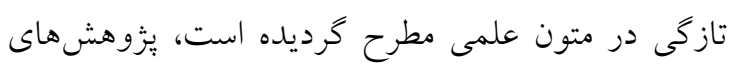

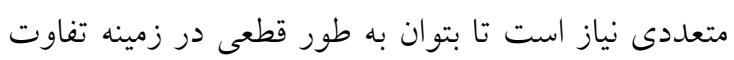

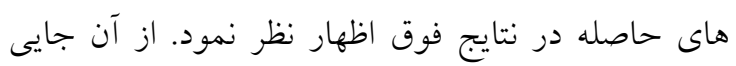

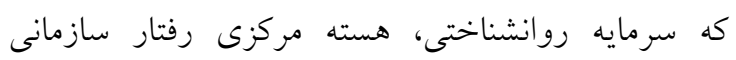

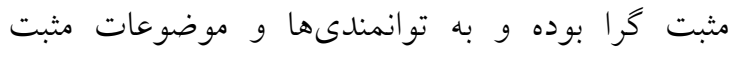

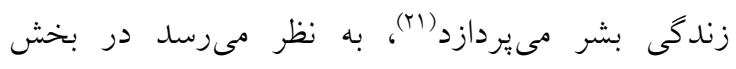

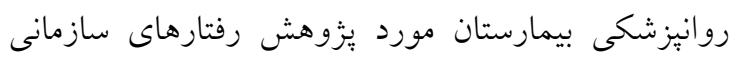

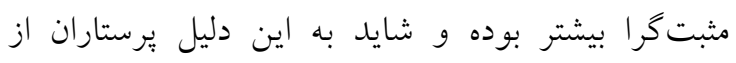
مهارت هاى ساز گارى بالاترى برخوردار بودهاند.

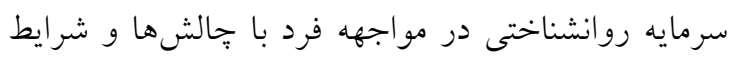

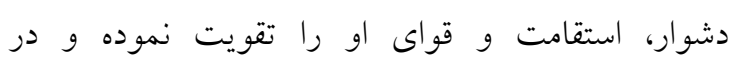

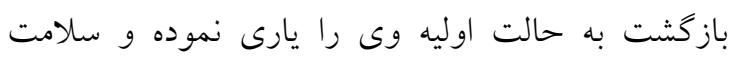

\section{بحث و نتيجهكيرى}

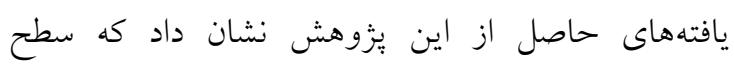

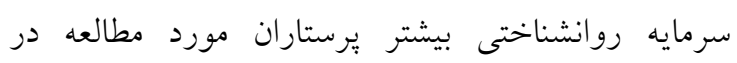

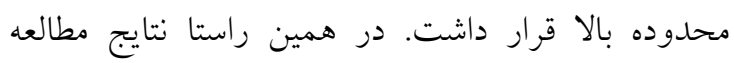
نظامى و همكاران كه با هدف "تعيين تأثير سرمايه

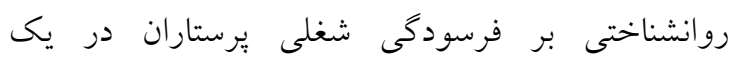

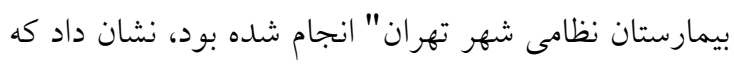

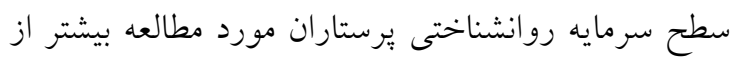

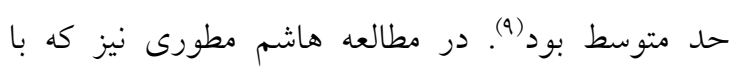

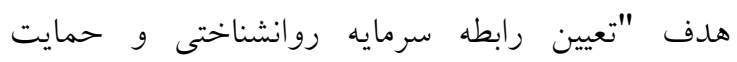

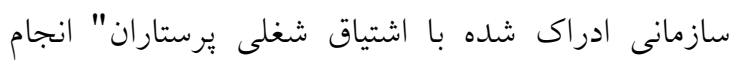

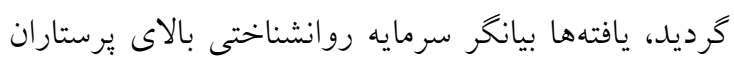

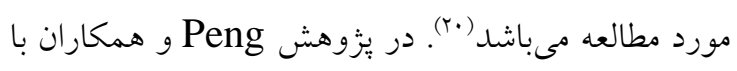

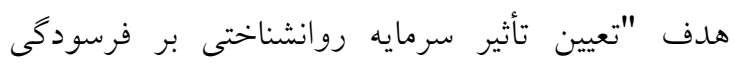

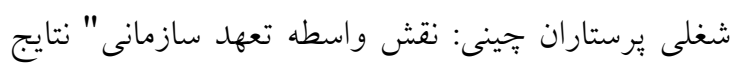

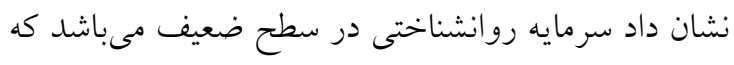
با مطالعه حاضر همسو نمى باشد (ז'). نتايج مطالعه مرادى 
كاركنان اميد بالاترى نسبت به رسيدن اهداف تعيين شده

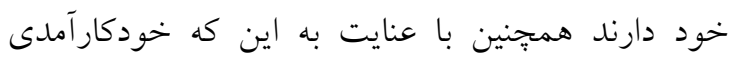

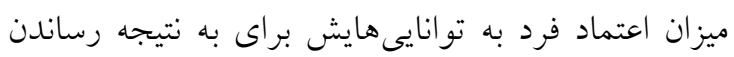

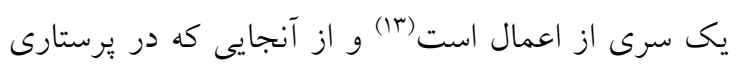

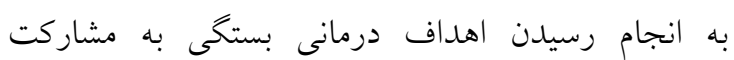

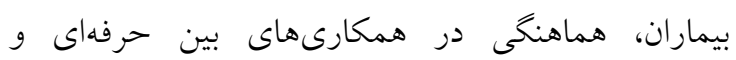

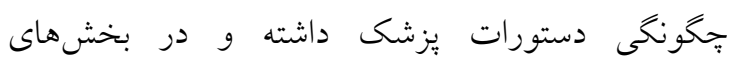
روانيزشكى مشاركت بيماران، همكارىهاى بين حرفهاى

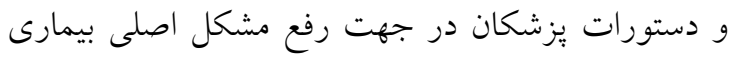

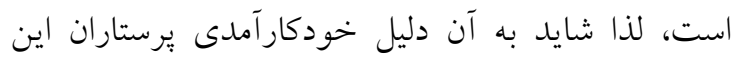
بخش نمره بالاترى را به خود اختصاص داده باشد.

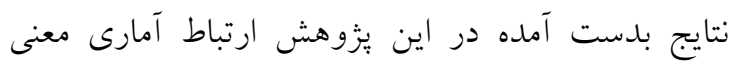

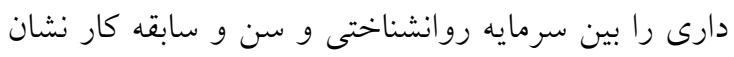

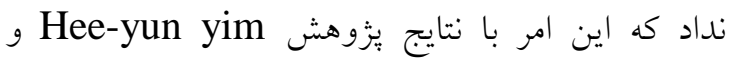
همكاران كه در بخشهاى مختلف بيمارستانى انجام

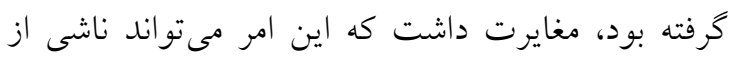

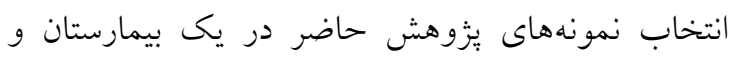

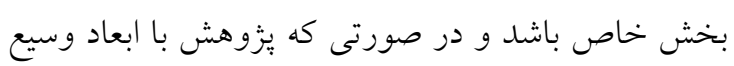

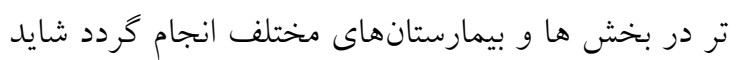
ارتباط عوامل جمعيت شناختى نيز تغيير يابد. همجنين

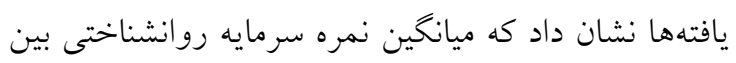

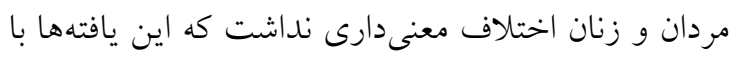

$$
\text { يزووهش فوق الذكر همسو بود (rع). }
$$

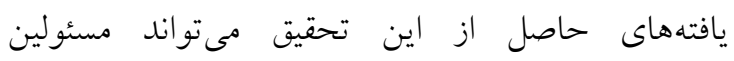

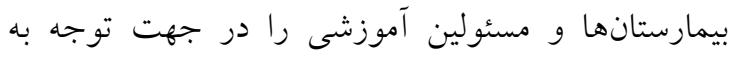

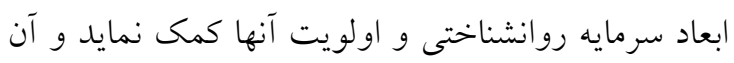
ها را در برنامهريزى جهت گنجاندن واحدهاى درسى در

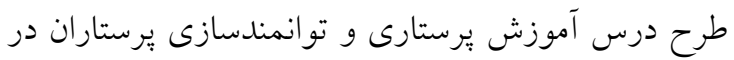
حيطه سرمايه روانشناختى يارى نمايد. با توجه به اين كه

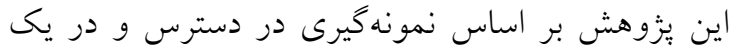

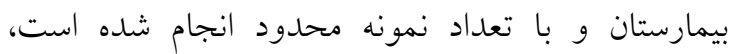
تعميم نتايج بايستى با احتياط صورت گيرد. بدين منظور

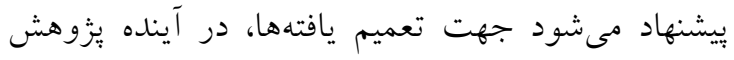

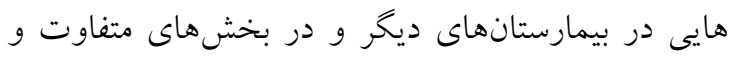

روانى و جسمى را به ارمغان مى آورد و منجر به رضايت

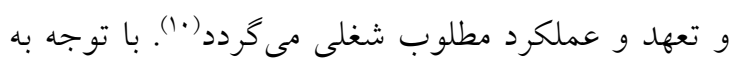

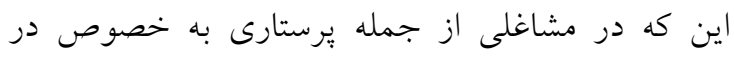
بخشهايى مثل بخشهاى روانيزشكى شرايط دشوارى

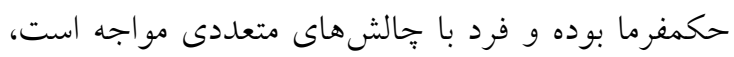

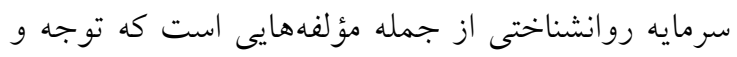

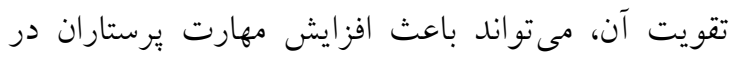

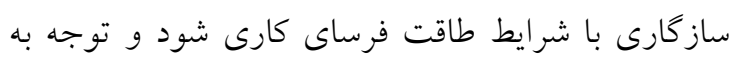
عوامل مؤثر بر سرمايه روانشناختى و ارتقاى سرمايه

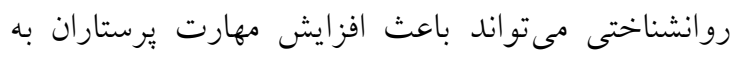
خصوص پرستاران بخشهاى روانيزشكى در سازكارى

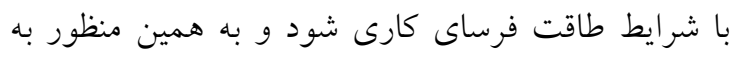
مديران توجه به ابعاد مختلف سرمايه روانشناختى بيشنهاد

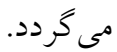
نتايج اين يزوهش نشان مىدهد كه در بين مؤلفههاى

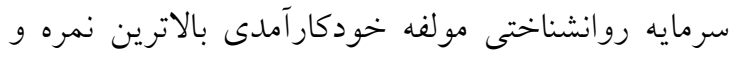

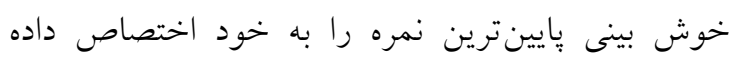

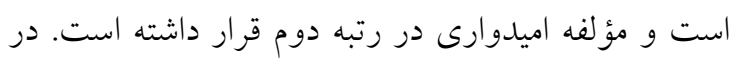

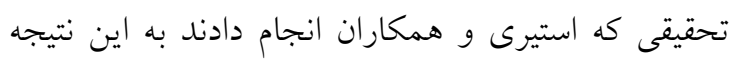

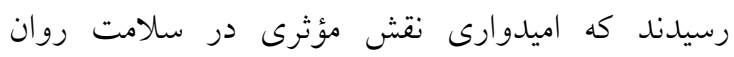
يرستاران داشته و در بالا بردن سرمايه روانشناختى آنها مؤثر است(rr) كه با نتايج مطالعه ما همخخوانى دارد. همجنين تحقيق هاشم مطورى و همكاران در شهر تهران

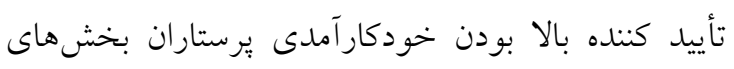

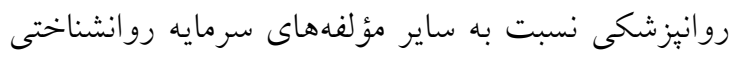
مىباشد كه با نتايج تحقيق فعلى همخوانى دارد (r.).

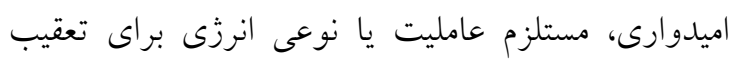
هدفها مىباشد و همجنين ديخر عنصر تشكيل دهنده اميدوارى، برنامه ريزى براى تحقق اهداف است كه نه

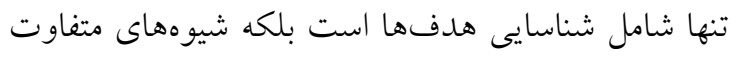

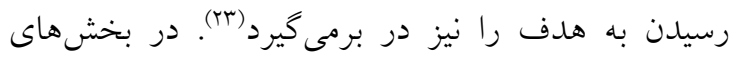
روانيزشكى به دليل وجود فرصت كافى براى تعيين اهداف و برنامهريزى و اجرا نسبت به بخشهاى دئر ديخر

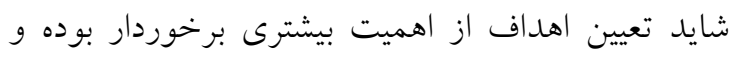


اين يُزوهش در راستاى پِيان نامه دانشجويى مقطع

كارشناسى ارشد برستارى با كد

كد اخلاق

در مركز تحقيقات دانشخاه آزاد اسلامى واحد اصفهان

(خوراسگان) انجام كرديده كه محققين از حوزه معاونت

يززوهشى اين دانشخاه كمال تشكر و قدردانى را مىنمايند.

همجنين محققان بر خود لازم مىدانند از مديريت محترم

و يرستاران بيمارستان كه با مشاركت خود انجام اين

$$
\text { يزوهش را مقدور نمودند، تشكر و قدردانى نمايند. }
$$

$$
\begin{aligned}
& \text { با روشهاى نمونه گيرى احتمالى نيز انجام گردد و } \\
& \text { همجنين بيشنهاد مى گردد در زمينه عواملى كه به صورت } \\
& \text { غيرمستقيم در بالا بردن سرمايه روانشناختى برستاران } \\
& \text { تأثير خذار هستند نيز مطالعاتى صورت يذيرد. } \\
& \text { تعارض منافع: هيج كونه تعارض منافع از سوى } \\
& \text { نويسند كان بيان نشده است. } \\
& \text { تقلدير و تشكر }
\end{aligned}
$$

\section{References:}

1. Mohammadi N, Sadri Demirchi E. Comparing the mental health and happiness among nurses of psychiatric and physical wards. Biomonthly official publication Daneshvar Medicine. 2017;25(131):73-80. [Persian]

2. Tavakkoli S, Asaadi MM, Pakpour AH, Hajiaghababaei M. Environmental psychology effects on mental health job satisfaction and personal well being of nurses. Iranian journal of psychiatry. 2015;10(3):158. [Persian]

3. Jafari E. Spiritual predictors of mental health in nurses: the meaning in life, religious well-being and existential well-being. The Journal of Urmia Nursing and Midwifery Faculty. 2015;13(8):676-84. [Persian]

4. Kheyri F, Seyedfatemi N, Oskouei F, Mardani-Hamooleh M. Nurses' mental health in Iran: a national survey in teaching hospitals. Scientific Journal of Kurdistan University of Medical Sciences. 2017;22(4):91-100. [Persian]

5. Soleimani R, Shokrgozar S, Kianmehr S, Fallahi M, Pakdaman M. Comparison of mental health and burn out in medical staff of Rasht Shafa and Heshmat Hospitals. Research in Medical Education. 2016;7(4):20-30. [Persian]

6. Jamali J, Ayatollahi SMT. Classification of Iranian nurses according to their mental health outcomes using GHQ-12 questionnaire: a comparison between latent class analysis and K-means clustering with traditional scoring method. Materia socio-medica. 2015;27(5):337-41.

7. Ferri P, Guadi M, Marcheselli L, Balduzzi S, Magnani D, Di Lorenzo R. The impact of shift work on the psychological and physical health of nurses in a general hospital: a comparison between rotating night shifts and day shifts. Risk management and healthcare policy. 2016;9:203-16.

8. Abdollahi D. Association of Educational Planning with Mental Health of Nursing Students of Tehran Medical Science University with Emphasis on the Educational Stressor Factors and Stress Management Methods. Iranian Journal of Health Education and Health Promotion. 2016;4(1):40-9. [Persian]

9. Nezami A, Givarian H. An investigation of the effect of psychological capital on the burnout of nurses in a military hospital in Tehran. Ebnesina. 2016;18(1):44-51. [Persian]

10. Moshtaghi S, Moayed FH. The role of psychological capital components (Hope, Optimism, Resiliency and Self-Efficacy) and Achievement goals Orientation in predicting Academic Procrastination in Students. Bioquarterly Journal of Cognitive Sterategies in Learning. 2017;5(8):61-78. [Persian]

11. Bayani AA, Bayani A, Rajabi A. The Relationship between Psychological Capital, Hope for Employment and Academic Burnout with Mental Health among Students of Islamic Azad University-Azadshahr Branch: A Path Analysis. Journal of Health Promotion Management. 2016;6(1):40-7. [Persian] 
12. Peng J, Jiang X, Zhang J, Xiao R, Song Y, Feng X, et al. The impact of psychological capital on job burnout of Chinese nurses: the mediator role of organizational commitment. PLoS One. 2013;8(12):e84193.

13. Sadoughi M, Mehrzad V, Mohammad Salehi Z. The relationship between psychological capital and quality of life among patients with breast cancer. Razi Journal of Medical Sciences. 2017;24(3):111-9. [Persian]

14. Khosroshahi JB, Nosratabad TH, Kheirodin JB. The relationship of psychological capital with social capital among students of Tabriz University. Journal of Research \& Health. 2012;2(1):6371. [Persian]

15. Teo S, Roche M, Pick D, Newton CJ. Psychological capital as moderator of organizational change demands on nursing stress. Pennsylvania Convention Center, Philadelphia, PA. 2014.

16. Wang X, Liu L, Zou F, Hao J, Wu H. Associations of occupational stressors, perceived organizational support, and psychological capital with work engagement among chinese female nurses. BioMed research international. 2017;2017(1):11-22.

17. Forohar M, Hovida R, Jamshidian R. Psychological capital and intraprunership among faculty members. Counseling Culture and Psychotherapy. 2012;2(8):83-100. [Persian]

18. McGee EA. An examination of the stability of positive psychological capital using frequencybased measurement. Tennessee Journal. 2011;87(5):100-9.

19. Golparvar M, Jafari M. Prediction of psychological capital through components of spirituality among nurses. Iranian Journal of Psychiatric Nursing. 2013;1(3):35-44. [Persian]

20. Hashem Matoori H. Investigating the Relationship between Psychological Capital and Perceived Organizational Support with Work Engagement among Nurses. Iranian Journal of Psychiatric Nursing. 2017;5(2):45-51. [Persian]

21. Moradi M, SadriDamirchi E, Khazan K, Dargahi S. The mediating role of psychological capital on the relationship between spiritual intelligence and job burnout. Journal of Occupational Health and Epidemiology. 2017;6(2):84-91. [Persian]

22. Estiri M, Nargesian A, Dastpish F, Sharifi SM. The impact of psychological capital on mental health among Iranian nurses: considering the mediating role of job burnout. SpringerPlus. 2016;5(1):1377.

23. Sareban $\mathrm{VH}$. The role of psychological capital in quality of life indicator at selected rural areas of Meshkinshahr. Geographic. 2014;12(42):239-55.

24. Yim H-Y, Seo H-J, Cho Y, Kim J. Mediating role of psychological capital in relationship between occupational stress and turnover intention among nurses at veterans administration hospitals in Korea. Asian nursing research. 2017;11(1):6-12. 